\title{
Design and Implementation of Agrobot with Automatic Sun Tracking
}

\author{
V. Radhika, B. Sharmila, R. Ramya, M. Gopisri
}

\begin{abstract}
Advancement in recent technology introduces the agriculture robotics. These robots can be harvesting stage, pesticide spraying, weed control, automatic milking and many other applications. These robots can replace the human labor and improve the production rate. To meet up the future demands and to overcome the disadvantages of the traditional methods, a agrobot that can do seed sowing along with soil testing process with automatic sun tracking solar panel manner is proposed in this paper. The agrobot will move around various ground contours, digs the ground, sows the desired number of seeds and cover it with the soil. Then adequate content of water is poured in to the ground according the texture of ground. This agrobot also do the soil testing process and the results of solid testing process can be viewed in the mobile phones through GSM module. This paper gives the complete installation details of the agricultural robot. This proposed agrobot is able to sow the seed, monitors the soil fertility, moisture content along with the automatic sun tracking solar panel.
\end{abstract}

Index Terms: Agrobot, Moisture Sensor, pH Sensor, Ultrasonic Sensor, Solar Panel.

\section{INTRODUCTION}

Agriculture is the practice of cultivating the soil for growing crops, fiber and many other products. It plays very important role in India's economy. In this modern world, process agriculture and farming is destroying due to short of human power as well due to the natural calamities. The conventional methods are less efficient and time consuming. The environmental changes greatly affect the agricultural production and the demand for the agricultural products is also increasing. Although agriculture is demolishing, at the same time technology for agriculture is also developing with the help of automation [1]. To overcome the difficulties undergone by the farmers, agriculture process is automated. Automation plays very job in improving almost all the industries in the current scenario. So, automation is implemented in the agricultural field to reduce the difficulties

Revised Manuscript Received on December 30, 2019.

* Correspondence Author

Dr.V.Radhika, Department of EIE, Sri Ramakrishna Engineering College, Coimbatore, India

Dr.B.Sharmila, Department of EIE, Sri Ramakrishna Engineering College, Coimbatore, India

Ms.Ramya, Department of EIE, Sri Ramakrishna Engineering College, Coimbatore, India

Ms.M.Gopisri, Department of EIE, Sri Ramakrishna Engineering College, Coimbatore, India

(C) The Authors. Published by Blue Eyes Intelligence Engineering and Sciences Publication (BEIESP). This is an open access article under the CC BY-NC-ND license (http://creativecommons.org/licenses/by-nc-nd/4.0/) undergone by the farmers. The technology for the cultivation operation in farming can be upgraded through the automation [2][3]. The modernization in the farming culture can bring a step in our traditional life style. The production can improved in agriculture through the equipments used for agriculture. This advancement in science and technology for agriculture can reduce the burden of the farmers. In this paper a GSM based Agrobot with Automatic Sun Tracking Solar Panel,a new technique is implemented. This agrobot can improve the production of food grains without affecting the quality of the soil. This also reduces the efforts of the agriculture workers and also maintains the fertility and moisture content of soil with help of the sensors. This proposed Agrobot with Automatic Sun Tracking Solar Panel do a lot of operations to reduce the difficulties of farmers. In new modern world, labor availability becomes the great concern for the farmers and cost for the labors is also very high. This proposed method minimizes the difficulties in sowing the seeds and in the testing process. In order to improvise the productivity of food grains, this technique has been proposed to automate the farming process.

This proposed method is designed with GSM module and Automatic Sun Tracking solar panel to sow the seeds with the help of the arms of agrobot. This agrobot works with the help of the solar energy through the automatic sun tracking solar panel. This automatic sun tracking solar panel towards to the side where there is the light source with the help of servo motor since it has Light Dependent Resistor. The fertility of soil is measured with electrochemical sensors and the moisture of the soil is monitored with help of moisture sensor. The obstruction in the field is sensed and its direction is monitored through the sensor. The moisture and fertility level is monitored with the help of sensors through the LabVIEW. Based on these results water is supplied to the field and fertilizer is sprayed. In this proposed work fertility can be measured with electrochemical sensors. This electrochemical sensors measures the nitrogen, phosphorus and potassium contents of the soil[4][5]. Conventional soil testing method is a three step process. It includes soil sampling, sample pretreatment and chemical analysis.

So the usage of electrochemical sensors reduces the time and also improves the efficiency of fertility measurement in the proposed system.

The moisture and fertility nature of the soil is sent to the farmers with the through the GSM module. This reduces burden of the farmer with the usage of the renewable solar energy. 


\section{PROPOSED METHOD}

Agro robot is developed with Arduino, Solar Panel, Moisture sensor, $\mathrm{pH}$ Sensor, Ultrasonic Sensor, Electrochemical sensor, Optical sensor and GSM module

The GSM-based Agrobot with Automatic Sun Tracking Solar Panel performs a number of concurrent operations. Today, the man power to do the farming is major concern, this machine removes the hurdles of agriculture labors. Their efficiency and operating speed greatly affects the productivity. This proposed method detects the obstacles, identifies the place for seed sowing, sows the seed ,monitors the fertility, moisture content of the soil[6]. The data from the different sensors is fed to the Arduino.The Arduino on receiving the above data operates the robot through the motor driver circuit. The robot is charged with the solar power through the solar activation system. The obstruction in the field is detected with the help of ultrasonic sensor and ground is digged to the specific predetermined distance. The moisture content of soil is also measured with the moisture sensor and $\mathrm{pH}$ sensor. The direction of movement of the robot is monitored with optical sensor[7]. The fertility nature of the soil is sensed using the electrochemical sensor. It detects the potassium, phosphorus and nitrogen conditions of the soil This makes the farmer easy to manure the soil and improve the cultivation.. The proposed methodology includes the soil monitorization using LabVIEW. GSM technology is used to communicate with the farmers for passing the information through SMS.

\section{EXPERIMENTAL SETUP}

The robot fixed with motor driver acts a heart of the proposed ork. Proposed Robot do the automatic irrigation process through the control of arduino with the measured parameters from sensor. The moisture content of the soil from the soil moisture sensor, $\mathrm{pH}$ from the soil $\mathrm{pH}$ sensor and fertility nature from the electrochemical sensor is detected. These collected data's are given to the Arduino. The data which are collected with the robotic setup is displayed with the help of suitable software. Arduino is connected with GSM module to send the information to the end user. This also controls the movement of the agro robot through the motor driver circuit. End user based on this information can manure and irrigate the soil.

The power supply is given to the arduino with the help of sun tracking solar panel system. The solar panel gets activated with the help of solar activation system which rotates along the direction of the sun. The agrobot moves with the help of the arduino programming which consists of IC Driver Circuit that amplifies the low power current to high with the help of $\mathrm{H}$ bridge circuit. The seed sowing process is done by using servo motor. The moisture sensor and the $\mathrm{pH}$ sensor connects to the arduino monitors the soil condition. The block diagram of the proposed method is shown in Fig.1.

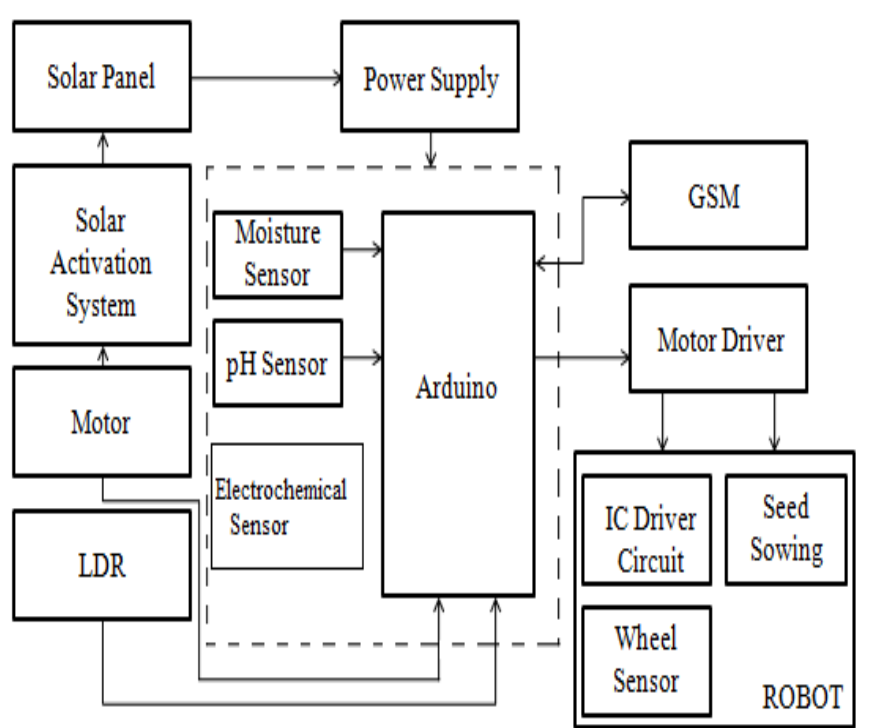

Fig.1 Block diagram of agro robot

\section{SOFTWARE DESCRIPTION}

Software which we used for work is

- Arduino

- LabVIEW

\section{A. Arduino}

Arduino is an open source software and it a single microcontroller board which consists of different types.The Arduino board which is used in the proposed robot is programmed through the Arduino Software.The output can be viewed through the serial monitor and serial plotter.

\section{B. LabVIEW}

Laboratory Virtual Instrument Engineering Workbench (LabVIEW) is a development environment and system-design platform for a visual programming language from National Instruments. The LabVIEW Software use a DAQ card to connect with the hardware. The sensors are connected with the DAQ card to get the output.

\section{RESULTS AND DISCUSSION}

The fig.2 shows the Agrobot with Automatic Sun Tracking Solar Panel using Arduino. The boat sows the seeds according to the given input distance and it senses the soil conditio. The output from the robot is shown in Fig.3. The movement of the robot is shown in Fig.4.

The weight of of the argobot is small to operate and handle. This further protect the human workers from the harmful effects in handling chemicals. This improves the fresh produce and also reduce labor cost. 


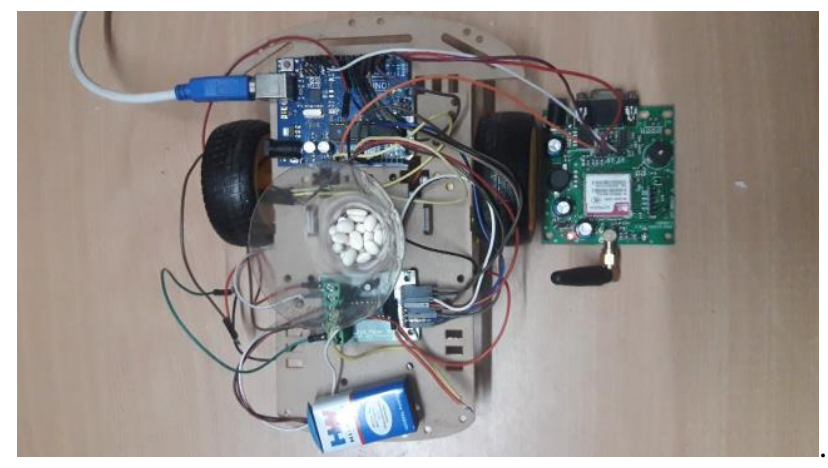

Fig.2 Agrobot

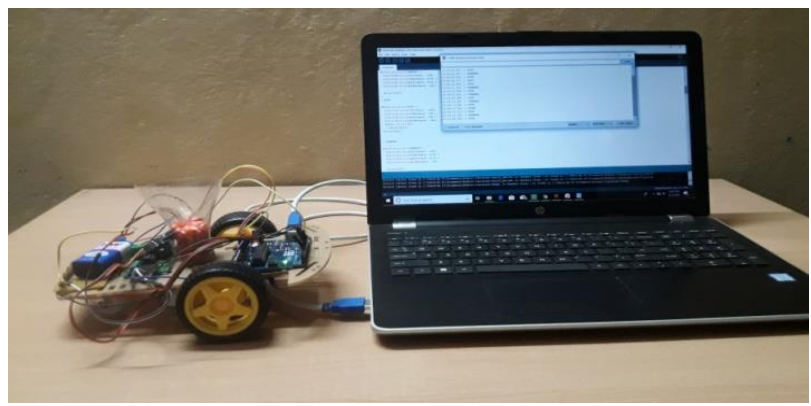

Fig.3 Agrobot connected with LabVIEW

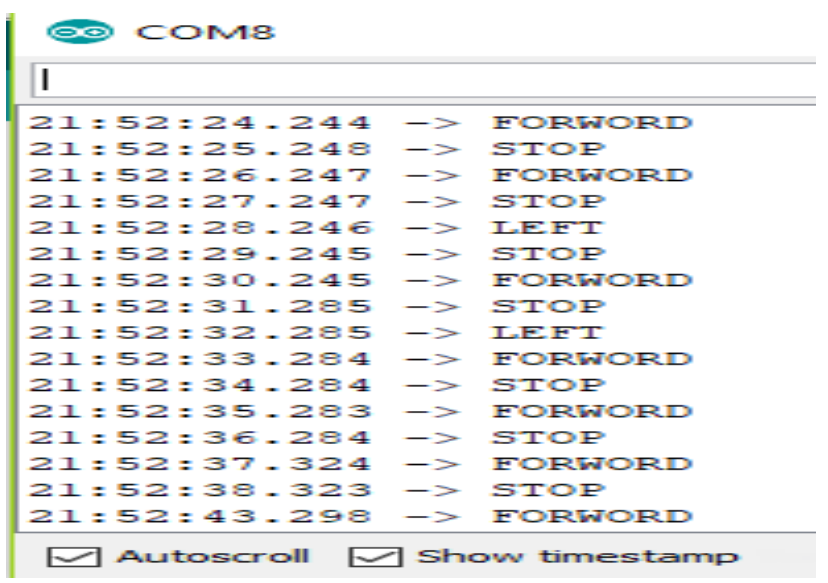

Fig.4 Agro robot connected results

\section{CONCLUSION}

The proposed system is automated and manages soil status effectively and efficiently and also reduces risk to farmers[8][9]. The proposed monitors and thus provides warning to the farmers about the nutrients, soil moisture content through given mobile number. The proposed method also sows seed and the maintains the enough spacing and it reduces the manual labor requirement. The proposed work is energized with the solar power and maintains energy conservation[10]. The proposed robot is designed for the improvement in the life of farmers.

\section{FUTURE SCOPE}

The proposed robot in this work can be further enhanced by adding various sensors like temperature sensor, tensiometer sensor and water mark sensors. The Agrobot can be extended through various wireless technologies to get good accurate results and improve the yield and quality of the crop. The webserver can be used to store and process the data received

from the sensor. This can improvise the monitoring system for the farmers.

\section{ACKNOWLEDGMENT}

Author thanks the Management of SNR Sons Charitable Trust, Principal and Head of the Department of Sri Ramakrishna Engineering College for their extensive help and support to complete the proposed work.

\section{REFERENCES}

1. P.Sreelakshmi,Gaggara Harika,Kavya Karat,"Automated Agrobot”, Indian Journal of Science and Technology,vol.9,No.4,pp.30-32,2016.

2. AnujaMohalkar, Priti Mohite, ShubhangiNagare, "Automatic Seed Sowing Machine using Solar Panel",International Journal Of Innovations in Engineering Research And Technology,vol.2,no.3,pp. 2394-2396, 2017

3. Thorat Swapnil V, Madhu L. Kasturi, Patil Girish V, Patil Rajkumar N "Design and Fabrication of Seed Sowing Machine", International Research Journal of Engineering and Technology (IRJET), vol.4,no.9,pp.704-707,2017.

4. Saurabh Umarkar and Anil Karwankar, "Automated Seed Sowing Agribot using Arduino", International Conference on Communication and Signal Processing, Vol.32,No.6,pp.6-8,2016

5. Sridevi P C, Mr. KhajaMoinuddin, "Design and Development of Automated Soil Quality Management System using LabVIEW", International Journal of Innovative Research in Electronics and Communications,vol.2,no.2,pp.8-15,2015.

6. Prof.PranilV.Sawalakhe,AmitWandhare,AshishSontakke, "Solar Powered Seed Sowing Machine",Global Journal of Advanced Research,Vol.2,No.3,pp.712-717,2015.

7. Mr.Sagar R. Chavan* , Prof. Rahul D. Shelke, Prof. Shrinivas R. Zanwar, "Enhanced Agriculture Robotic System", International Journal of Engineering Sciences and Research Technology,vol.4,no.2,pp.368-371,2015.

8. Calvin Hung, Juan Nieto, Zachary Taylor, James Underwood and Salah Sukkarieh, "Orchard Fruit Segmentation using Multi-spectral Feature Learning",International Conference on Intelligent Robot System, vol.4,no.3,pp.3-7,2013.

9. Shrinivas R. Zanwar, R. D. Kokate, "Advanced Agriculture System", International Journal of Robotics and Automation,Vol.1, No. 2, pp. 107-112,2012

10. Chengliang Liu, Mingjun Wang, and Jun Zhou, "Coordinating control for an agricultural vehicle with individual wheel speeds and steering angles", IEEE control systems magazine,vol.2,no.3,pp.21-25,2008

\section{AUTHORS PROFILE}

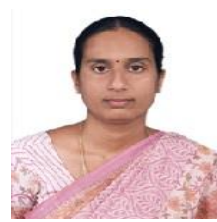

Dr. V. Radhika, Associate Professor from the Department of Electronics and Instrumentation, Sri Ramakrishna Engineering College, Coimbatore. She completed her Doctoral Degree in the Faculty of Information and Communication Engineering in Anna University Chennai.. She is professional member of IEEE, ISOI and ISTE. She has published more than fifteen papers in National and International Journals.

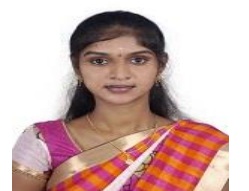

Mrs.R.Ramya, Assistant Professor in the Department of Electronics and Instrumentation, Sri Ramakrishna Engineering College, Coimbatore. She has completed her Master Degree from Anna University, Chennai. She is professional member of ISOI and ISTE. She has published more than ten papers in National and International Journals

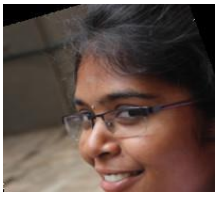

Ms. M.Gopisri, Final year student of Department of Electronics and Instrumentation, Sri Ramakrishna Engineering College, Coimbatore

Published By:

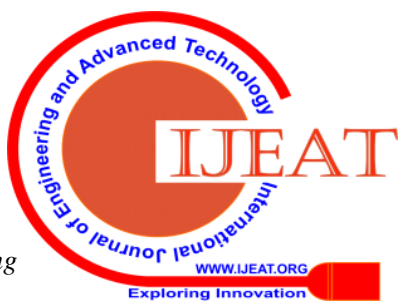

